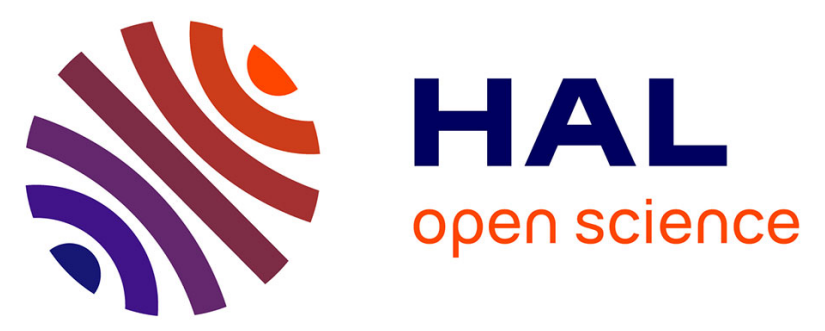

\title{
Factors associated with the emergence of integrase resistance mutations in patients failing dual or triple-integrase inhibitors-based regimen in a French national survey
}

Anne-Genevieve Marcelin, Charlotte Charpentier, Pantxika Bellecave, Basma Abdi, Marie-Laure Chaix, Virginie Ferre, Stephanie Raymond, Djeneba Fofana, Laurence Bocket, Audrey Mirand, et al.

\section{- To cite this version:}

Anne-Genevieve Marcelin, Charlotte Charpentier, Pantxika Bellecave, Basma Abdi, Marie-Laure Chaix, et al.. Factors associated with the emergence of integrase resistance mutations in patients failing dual or triple-integrase inhibitors-based regimen in a French national survey. Journal of Antimicrobial Chemotherapy, 2021, 76 (9), pp.2400-2406. 10.1093/jac/dkab193 . hal-03388629

\section{HAL Id: hal-03388629 \\ https://hal.sorbonne-universite.fr/hal-03388629}

Submitted on 20 Oct 2021

HAL is a multi-disciplinary open access archive for the deposit and dissemination of scientific research documents, whether they are published or not. The documents may come from teaching and research institutions in France or abroad, or from public or private research centers.
L'archive ouverte pluridisciplinaire HAL, est destinée au dépôt et à la diffusion de documents scientifiques de niveau recherche, publiés ou non, émanant des établissements d'enseignement et de recherche français ou étrangers, des laboratoires publics ou privés. 
1 Factors associated with the emergence of integrase resistance mutations in patients failing

dual or triple-integrase inhibitors-based regimen in a French national survey

Anne-Genevieve MARCELIN ${ }^{1}$, Charlotte CHARPENTIER ${ }^{2}$, Pantxika BELLECAVE ${ }^{3}$, Basma ABDI $^{1}$, Marie-Laure CHAIX ${ }^{4}$, Virginie FERRE ${ }^{5}$, Stephanie RAYMOND ${ }^{6}$, Djeneba FOFANA ${ }^{7}$, Laurence BOCKET ${ }^{8}$, Audrey MIRAND ${ }^{9}$, Helene LE GUILLOU-GUILLEMETTE ${ }^{10}$, Brigitte MONTES $^{11}$, Corinne AMIEL ${ }^{12}$, Coralie PALLIER ${ }^{13}$, Samira FAFI-KREMER ${ }^{14}$, Anne DE MONTE $^{15}$, Elodie ALESSANDRI-GRADT ${ }^{16}$, Caroline SCHOLTES $^{17}$, Anne MAILLARD ${ }^{18}$, Helene JEULIN ${ }^{19}$, Magali BOUVIER-ALIAS ${ }^{20}$, Catherine ROUSSEL ${ }^{21}$, Georges DOS SANTOS ${ }^{22}$, Anne SIGNORI-SCHMUCK ${ }^{23}$, Julia DINA ${ }^{24}$, Sophie VALLET ${ }^{25}$, Karl STEFIC ${ }^{26}$, Cathia SOULIÉ $^{1 *}$, Vincent CALVEZ ${ }^{1}$, Diane DESCAMPS ${ }^{3}$, Philippe FLANDRE ${ }^{27}$, on behalf of the ANRS-MIE AC43 group †.

${ }^{1}$ Sorbonne Université, INSERM, Institut Pierre Louis d'Epidémiologie et de Santé Publique, APHP, Hôpitaux Universitaires Pitié Salpêtrière - Charles Foix, laboratoire de virologie, F75013, Paris, France; ${ }^{2}$ Service de Virologie, Université de Paris INSERM, IAME, UMR 1137, AP-HP, Hôpital Bichat,-Claude Bernard, F-75018 Paris, France; ${ }^{3}$ CHU de Bordeaux, Laboratoire de Virologie, Univ. Bordeaux, CNRS UMR 5234, F-33076 Bordeaux, France $;{ }^{4}$ INSERM U941, Université de Paris, Laboratoire de Virologie, AP-HP, Hôpital Saint-Louis, Paris, France; ${ }^{6}$ INSERM UMR 1291 Toulouse, F-31300 France and Laboratoire de Virologie, CHU Toulouse Purpan, Toulouse, F-31300 France; ${ }^{7}$ AP-HP, CHU Saint Antoine, INSERM-Sorbonne Universités, UPMC Univ Paris 06, UMR_S 1136, Paris, France; ${ }^{8}$ Univ. Lille, CHU Lille, Laboratoire de Virologie, Lille, France; ${ }^{9}$ CHU de Clermont-Ferrand, France; ${ }^{10}$ Laboratoire de Virologie, CHU Angers and HIFIH Laboratory EA 3859, LUNAM, Angers, France ; ${ }^{11}$ Laboratoire de Virologie, CHU Montpellier, Univ Montpellier, France ; ${ }^{12}$ AP-HP, CHU Tenon, Paris, France ; ${ }^{13}$ CHU Paul Brousse, Villejuif, 
France ; ${ }^{14}$ CHU de Strasbourg, Strasbourg, France ; ${ }^{15}$ CHU de Nice, Nice, France ; ${ }^{16}$ CHU de Rouen, Université de Rouen Normandie UNIRouen, France $;{ }^{17}$ INSERM U1052, CRCL, Université de Lyon, Laboratoire de Virologie; ${ }^{18}$ Laboratoire de Virologie, CHU de Rennes, Rennes, France ;

${ }^{19}$ Laboratoire de Virologie, CHRU de Nancy Brabois, Vandoeuvre-lès-Nancy ; ${ }^{20}$ CHU Henri Mondor, Laboratoire de Virologie, Créteil, France ; ${ }^{21}$ CHU d'Amiens, Amiens, France ; ${ }^{22}$ Service de virologie, CHU de Martinique, Fort de France, Martinique; ${ }^{23}$ CHU Grenoble-Alpes, Grenoble, France ; ${ }^{24}$ Normandie Univ, UNICAEN, UNIROUEN, GRAM 2.0, Caen University Hospital Department of Virology, F14000, France; ${ }^{25}$ Laboratoire de Virologie, CHRU de Brest, Brest, France ; 26 INSERM U1259, Université de Tours et Laboratoire de Virologie, CHRU de Tours, Tours, France ; ${ }^{27}$ INSERM-Sorbonne Universités, UPMC Univ Paris 06, UMR_S 1136, Paris, France.

\section{* Corresponding author}

Mailing address: Department of Virology, Pitié-Salpêtrière Hospital, 83 Boulevard de l'Hôpital, 75013 Paris, France. Phone : 33142177401 , Fax : 33142177411.

e-mail: cathia.soulie-ext@aphp.fr

$\dagger$ Members are listed in the Acknowledgement section

Running title: HIV resistance to integrase inhibitors

Prior presentation: European Meeting on HIV and Hepatitis 2020 (oral presentation n ${ }^{4}$ ).

Word count: 2166 


\section{ABSTRACT}

Objectives: Successful 2 drug regimens (DR) were made possible by the availability of drugs combining potency and tolerability with high genetic barrier to resistance. How these approaches would deal with resistance development/re-emergence, compared with 3DR, is thus of paramount importance.

Material and Methods: A national survey including patients failing either naive or experienced (2 consecutive plasma viral load (VL) $>50$ copies/mL) to any 2DR or 3DR integrase inhibitors (INSTI)-containing regimens was conducted between 2014 and 2019. Genotypic resistance tests were interpreted with the v28 ANRS algorithm.

Results: 1104 patients failing to any INSTI-containing regimen $(2 \mathrm{DR}=207$ and 3DR=897) were analysed. 577 (52.3\%) patients were infected with a B subtype and 527 (47.3\%) with non-B subtypes. Overall, 644 (58\%) patients showed no known integrase resistance mutations at failure. In multivariate analysis, factors associated with the emergence of at least one integrase mutation were high $\mathrm{VL}$ at failure $\left(\mathrm{OR}=1.24\right.$ per $1 \log _{10}$ copies/mL increase $)$, non-B versus $\mathrm{B}$ subtype $(\mathrm{OR}=$ 1.75), low genotypic sensitivity score $(\mathrm{GSS})(\mathrm{OR}=0.10$ for $\mathrm{GSS}=2$ versus $\mathrm{GSS}=0-0.5)$, dolutegravir versus raltegravir $(\mathrm{OR}=0.46)$. Although 3DR versus 2DR reach statistical significance in univariate analysis $(\mathrm{OR}=0.59, \mathrm{p}=0.007)$, the variable is not retained in the final model.

Conclusions: This study is one of the largest studies characterizing integrase resistance in patients failing to any INSTI-containing 2DR or 3 DR regimen in routine clinical care and reveals factors associated with emergence of integrase resistance that should be taken into consideration in clinical management. No difference was evidenced between patients receiving 2DR or 3DR. 
For approximately 20 years, triple therapy has been the dogma of antiretroviral therapy (ART) for naive HIV-1 patients, and also in the switch context for previous antiretroviral-treated HIV-1 patients. Nowadays, considering the lifelong ART and the need to decrease the potential adverse effects of drug exposure, some alternative strategies have been introduced and especially 2 drugs regimen (DR).

Some clinical trials have demonstrated a similar proportion of virological HIV suppression between 2DR and 3/4DR for switch strategies, especially with an integrase strand transfer inhibitor (INSTI): dolutegravir and lamivudine (ASPIRE, LAMIDOL, TANGO), dolutegravir and rilpivirine (SWORD), cabotegravir and rilpivirine (LATTE, FLAIR, ATLAS). ${ }^{1-7}$ Then, the GEMINI clinical trial (dolutegravir and lamivudine) has been conducted in antiretroviral naive HIV-1 patients and evidenced a similar efficacy of the 2DR and 3DR (dolutegravir and tenofovir disoproxil fumarate/emtricitabine) as in the NEAT001/ANRS143 (raltegravir and darunavir) clinical trial. ${ }^{8-10}$ However, in this latter trial, emergence of resistance mutations was higher in the raltegravir and darunavir/ritonavir group. ${ }^{11}$

The European AIDS Clinical society (EACS) and US-based guidelines have recommended now the 2 and 3DR with INSTI for both antiretroviral naive and experienced HIV patients. In the case of 2DR for initiation of ART, dolutegravir and lamivudine were approved in patients without hepatitis B antigen, HIV viral load $<500000$ copies/mL. ${ }^{12,13}$

All these studies focused on the virological efficacy of the 2DR versus 3DR, but few data are available on the HIV-1 resistance in case of virological failure and the factors associated with. Our aim was to identify the emergence of INSTI resistance associated mutations (RAM) in failing patients receiving an INSTI-based dual or a triple therapy. In these patients, we investigated baseline variables and the level of viral load at failure associated to at least one INSTI RAM. The aim was, 
in particular to distinguish between the effect of the following factors (i) receiving a dual or triple therapy, (ii) the genotypic sensitivity score (GSS) associated to the non INSTI drugs in the regimen, and (iii) the INSTI received (raltegravir, elvitegravir or dolutegravir).

\section{PATIENTS AND METHODS}

\section{$\underline{\text { Patients and antiretroviral regimens }}$}

HIV-1-infected patients followed in the 21 participating virology laboratories labelled ANRS-MIE AC43 and who experienced virologic failure, defined as two consecutive HIV-1 viral loads (VL) > 50 copies/mL, to an INSTI-containing regimen between 2014 and 2019 were included in the study. All data were checked by a study monitor.

\section{Ethics}

Individual antiretroviral agents were recorded along with their dates of initiation and discontinuation, if applicable. All patients gave written informed consent that a de-identified, electronic version of their medical chart could be used for research purposes. The study was approved by the scientific committee of the ANRS-MIE AC43.

\section{Genotypic resistance testing}

The virology laboratories belonging to the ANRS-MIE AC43 network have participated annually in the ANRS-MIE quality control assessment of HIV-1 drug resistance sequencing. ${ }^{14}$ The HIV protease (PR), reverse transcriptase (RT) and integrase (IN) sequences were determined in each participating laboratory on plasma obtained to confirm virological failure. Three different methods were used: the ANRS-MIE consensus technique (http://www.hivfrenchresistance.org/), the 
Abbott ViroSeq kit, or an in-house method. For resistance interpretation (resistant, intermediate or susceptible), the ANRS algorithm (Version 28) was used (www.hivfrenchresistance.org).

The GSS of the current regimen (without INSTI) was calculated according to the ANRS algorithm as follows: susceptible GSS $=1$, intermediate $\mathrm{GSS}=0.5$, resistance $\mathrm{GSS}=0$.

The studied INSTI RAM were: T66A/I/K, L74F/I/M, V75I, E92Q, T97A, G118R, F121Y, E138A/K/T, G140A/C/S, Y143A/C/G/H/R/S, P145S, S147G, Q148EG/H/K/R, V151L, S153F/Y, N155H/S/T, E157Q, S230R, R263K.

\section{$\underline{\text { Statistical analysis }}$}

Quantitative variables are described by median and Interquartile Range (IQR) while categorical variables are described in percent. HIV-1 RNA at baseline and at failure, viral subtype (B versus non-B), baseline CD4 cell count, CD4 nadir, age, duration of infection, duration of INSTI treatment, type of ongoing treatment (dual versus triple therapy), GSS and INSTI molecule received were investigated as potential factors of occurrence of at least one INSTIs mutation by a logistic regression model. All variables tested with a $\mathrm{P}$-value $<0.10$ in the univariate analysis were retained for building the final multivariate model using a stepwise selection. Comparison between groups of patients were carried out using either Fisher's exact test for categorical variables or Kruskal-Wallis test for continuous variables.

\section{RESULTS}

Overall, 1104 patients failing an INSTI-containing regimen and receiving either 2DR (n=207) or 3DR $(n=897)$ were included in the study from 21 French centers of the ANRS-MIE network. Patients' characteristics are displayed in Table 1. Patients were failing while receiving raltegravir $(n=430)$, elvitegravir $(n=323)$ or dolutegravir $(n=351)$ containing regimen. Overall, $782(71 \%)$ patients were failing their first line of INSTI-containing regimen of whom 160 patients were on their 
first-line ART. Patients on 2DR were slightly older (median 52 versus 47 years-old, $\mathrm{p}<0.001$ ), had an older history of HIV infection (median 20.6 versus 12.8 years, $\mathrm{p}<0.001$ ), had a higher median of baseline CD4 cell count (460 versus 360 cells $/ \mathrm{mm}^{3}, \mathrm{p}<0.001$ ) and a higher median of duration of the current INSTI regimen (20.2 versus 13.5 months, $\mathrm{p}<0.001)$. As expected, the median GSS score was higher for patients in 3DR than patients in the 2DR group (median 2 versus $1, \mathrm{p}<0.001$ ). A majority $(62 \%)$ of patients were male with and subtype B was the predominant HIV-1 clade (52\%). In 2DR group, the INSTI was preferentially associated with one PI in 53\% of cases or with one NNRTI in $35 \%$ of cases. In the 3DR group, $87 \%$ of patients received a combination of two NRTIs in association with the INSTI. At failure, median VL was $2.9 \log _{10}$ copies/mL (IQR: 2.3-4.0) with higher median levels in patients with lower GSS (3.4, 3.2 and $2.9 \log _{10}$ copies/mL in patients with GSS of [0-0.5], [1-1.5] and [2], respectively).

Among the 1104 failing patients, 460 (42\%) patients had viruses carrying INSTI RAM: 1, 2, 3 and at least 4 mutations in $286(26 \%), 110(10 \%), 44(4 \%)$ and $20(2 \%)$ patients, respectively. The repartition of patients with at least one INSTI RAM was as follow: 52\% in the 2DR group and 39\% in the 3DR group. Overall, N155H/S/T and L74F/I/M were the most commonly mutations observed in $15 \%$ and $14 \%$ of patients, respectively (Figure 1). The largest difference was observed for the $\mathrm{N} 155 \mathrm{H} / \mathrm{S} / \mathrm{T}$ mutation which was found in $105(24 \%), 49(15 \%)$ and $10(3 \%)$ of patients receiving raltegravir, elvitegravir and dolutegravir, respectively. To note, INSTI RAM were distributed differently according to the HIV-1 subtype in our population as L74F/I/M and E157Q were overrepresented in HIV-1 non-B subtype versus B subtype patients $(21.1 \%$ versus $8.5 \%$ and $4.7 \%$ versus 2.1\%) while G140C/H/S and Q148EG/H/K/R were higher in HIV-1 B subtypes (5.5\% versus $1.3 \%$ and 8.0 versus $3.6 \%$ ). Figure 2 shows the genotypic interpretation of integrase resistance to different INSTIs among the 1104 patients failing an INSTI-containing regimen. Overall, resistance to INSTI was lower for patients failing dolutegravir $(8 \%)$ in comparison with patients failing raltegravir (41\%) and elvitegravir (37\%). 
We aimed to characterize clinical and virological factors associated with the emergence of at least one INSTI RAM (Table 2). Several factors were retained for the multivariable analysis: 3DR versus 2DR ( $\mathrm{p}=0.007)$, HIV RNA viral load at failure $(\mathrm{p}<0.0001)$, duration of INSTIs treatment $(\mathrm{p}=0.003)$, duration of infection ( $\mathrm{p}=0.09)$, HIV subtype $(\mathrm{p}=0.10)$, GSS $\mathrm{p}<0.0001)$, and antiretroviral treatment: dolutegravir versus raltegravir $(\mathrm{p}<0.0001)$; elvitegravir versus raltegravir $(\mathrm{p}=0.08)$. The final multivariate model showed that a higher risk of occurrence of INSTI RAM was associated with a higher VL at failure $\left(\mathrm{OR}=1.24\right.$ per $1 \log _{10}$ copies/mL increase) and with HIV-1 non-B subtype ( $\mathrm{OR}=1.75$ versus $\mathrm{B}$ subtype). A lower risk was observed with a higher GSS level (OR=0.32 for $\mathrm{GSS}=1-1.5$ and $\mathrm{OR}=0.10$ for $\mathrm{GSS}=2$ versus $\mathrm{GSS}=0-0.5$ ) and dolutegravir-containing regimen ( $\mathrm{OR}=0.46$ versus raltegravir). To note, if the $\mathrm{L} 74 \mathrm{~F} / \mathrm{I} / \mathrm{M}$ and $\mathrm{E} 157 \mathrm{Q}$ RAMs were removed from the analysis, the HIV subtype hasn't longer remained as an associated factor of the emergence of the INSTI RAM (Table S1).

\section{DISCUSSION}

The current expanding use of integrase inhibitors and 2DR for both naive and suppressed HIV-1 patients evidence the need for large clinical routine care studies to evaluate the integrase resistance in case of virological failure and the factors associated with. This study evidenced that less than half of HIV patients failing an INSTI regimen harbored viruses with at least one integrase RAM. Two factors were independently associated with a higher risk of occurrence of integrase RAM, HIV-1 RNA VL at failure and HIV-1 non-B subtype. On the contrary, a lower risk was associated with a higher GSS and a dolutegravir based regimen. Furthermore, there was no difference regarding the antiretroviral strategy, 2DR versus 3DR, on the emergence of integrase RAM.

Overall, among this large cohort of HIV-1 patients failing INSTI based regimen and followed in the hospital clinical care, about less than half of rebound viruses carried INSTI RAM. These results are 
in accordance with those of our previous national studies and some cohorts. ${ }^{15-18}$ However, these rates may seem higher than described in other cohorts, but this could be explained by several factors as the defined list of INSTI mutations (major mutations or polymorphisms), the INSTI studied (first and/or second generation), the patients' characteristics (immunological and virological factors) and the time under INSTI treatment. ${ }^{19-21}$ Furthermore, in comparison with the first studies on INSTI resistance, some patients had been receiving INSTI for several years.

The most common INSTI RAM found in our study were L74F/I/M and N155H/S/T. This higher prevalence of N155H/S/T was also evidenced in Italian, English and Argentinian cohorts. ${ }^{17,18,22,23}$ The prevalence of this mutation was different according to the INSTI, with a lower prevalence for patients failing dolutegravir. Overall, the level of INSTI genotypic resistance was lower for patients failing dolutegravir than for patients failing raltegravir and elvitegravir regimen and this is in accordance with our previous national survey. ${ }^{15}$ This could be explained by a higher affinity of dolutegravir for its target and therefore a higher genetic barrier to resistance. ${ }^{24-26}$ In general, it is now admitted that emerging resistance during dolutegravir failure is rare and observed mostly in ARV-experienced patients in comparison to the first generation of INSTIs. ${ }^{27}$ The results of our multivariate analysis were consistent as the use of dolutegravir in the antiretroviral treatment was associated to a lower risk of RAM acquisition.

Considering the occurrence of at least one INSTI RAM, the multivariate analysis showed a higher risk with a higher level of HIV-1 VL at failure and a lower risk with a higher level of GSS. In a previous study focusing on raltegravir, a lower GSS and a higher HIV-1 VL level at failure (>1000 copies/mL) were associated with the presence of raltegravir RAM. ${ }^{16}$ Usually, a higher VL and/or a lower CD4 count at baseline were associated with more treatment failures in a cohort of HIV-1 patients with first line integrase inhibitor based antiretroviral treatment, but in this study the link between treatment failure and resistance mutations emergence was not evaluated or established. ${ }^{28}$ 
Overall, HIV-1 subtype seemed also to influence the occurrence of at least one integrase RAM with a higher risk of non-B subtypes. However, the HIV-1 subtype was no longer associated with the emergence of INSTI RAM when L74F/I/M and E157Q were removed of the analysis. Indeed, the distribution of INSTI RAM was different according to the HIV-1 subtype, as L74F/I/M and E157Q were mostly present for HIV-1 non-B subtypes although G140C/H/S and Q148EG/H/K/R for B subtype. Two previous studies demonstrating a higher prevalence of mutations at positions Q148 for HIV-1 B subtype for patients only receiving raltegravir as INSTI in their antiretroviral treatment. 16,23 Two limitations of our study appeared concerning the HIV subtype leverage: the absence of HIV-1 baseline genotypes and the lack of adherence data or pharmacological measurements of the patients to explore the hypothesis of an adherence difference according to the HIV-1 subtype.

Some authors suggested a possible weakness of the 2DR strategy which could allow a viral escape and selection of RAM. In our study, conditionally to other factors such as GSS and INSTI, no difference between 2DR and 3DR was observed in terms of occurrence of RAM. This result confirmed in a large cohort of clinical routine care the robustness of 2DR including an INSTI with no consequence on HIV resistance. Indeed, other studies showed no difference in achieving virological and a limited or no emergence of INSTI RAM in patients failing a 2DR with dolutegravir. ${ }^{3,8,29}$ However, we cannot generalize this conclusion to every 2DR regimen, as $53 \%$ of 2DR treated patients were receiving a PI in combination with an INSTI.

Overall, this study is one of the largest studies conducted in patients failing to any INSTI-containing 2DR or 3DR regimen in routine clinical care, and showing that a higher HIV RNA VL and HIV-1 non-B subtypes were associated with a higher risk of emergence of integrase RAM. Conversely the use of dolutegravir was associated with a lower risk of emergence of integrase RAM and no difference was evidenced between patients receiving $2 \mathrm{DR}$ or 3DR. These results should be taken into consideration in patients' clinical management. 
Members of the ANRS AC43 Resistance Study Group by location

Amiens, C. Roussel; Angers, H. Le Guillou-Guillemette, A. Ducancelle ; Argenteuil, L. Courdavault; Avicenne, C. Alloui, P. Honore; Besançon, Q. Lepiller, D. Bettinger; Bordeaux, P. Bellecave, P. Pinson-Recordon, C. Tumiotto, S. Reigadas; Brest, S. Vallet, C Payan, JC. Duthe; Caen, M. Leroux, J. Dina, A. Vabret; Clermont-Ferrand, A. Mirand, C. Henquell; Créteil-Henri Mondor, M. Bouvier-Alias; Dijon, A. Simohamed ; Fort de France, G. Dos Santos; Genève, S. Yerly, C. Gaille, W. Caveng, S. Chapalay, A. Calmy; Grenoble, A. Signori-Schmuck, P Morand; HU Paris Sud, C. Pallier, M. Raho-Moussa, M. Mole, M-J. Dulucq; Lille-Tourcoing, L. Bocket, K.Alidjinou; Limoges, S. Ranger-Rogez; Lyon, M. A. Trabaud, V Icard, J.C. Tardy; Marseille, C. Tamalet; Metz/Thionville, C. Delamare; Montpellier, B. Montes; Nancy, E. Schvoerer, H. Fenaux; Nantes, A. Rodallec, E. André-Garnier, V. Ferré; Nice, A. De Monte; Orléans, A. Guigon, J. Guinard; Paris-Bichat Claude Bernard, D. Descamps, C. Charpentier, B Visseaux, G. Peytavin; Paris-Necker, M. Fillion; Paris-Pitié-Salpêtrière, C. Soulié, I. Malet, M. Wirden, A. G. Marcelin, V. Calvez, P. Flandre, L. Assoumou, D. Costagliola; Paris-Saint Antoine, L. Morand-Joubert, S. Lambert-Niclot, D. Fofana; Paris-Saint Louis, C. Delaugerre, ML Chaix, N. Mahjoub; Paris-Tenon, C. Amiel; Poitiers, G. Giraudeau, A. Beby-Defaux, D. Plainchamp; Rennes, A. Maillard; Rouen, E. Alessandri-Gradt, M. Leoz, J. C. Plantier; Strasbourg, P. Gantner S. Fafi-Kremer, P. Fischer ; Toulouse, S. Raymond, J. Izopet, J Chiabrando; Tours, F. Barin, G. Fajole, O. Burgault; Versailles, S. Marque Juillet.

\section{Members of the ANRS Clinical Centres by location}

Angers, P. Abgueguen, V. Rabier, Y.M. Vandamme; Besançon, B. Hoen; Bordeaux, M. Dupon, P. Morlat, D. Neau; Brest, M. Garré, V. Bellein; Caen, R. Verdon, A. De la Blanchardière, S. Dargère, 
A. Martin, V. Noyou; Clermont-Ferrand, C. Jacomet; Créteil, J.D. Lelièvre, J.L. Lopez-Zaragoza.; Dijon, B. Lorcerie; Fort de France, A. Cabié; Genève, S. Yerly; Grenoble, P. Leclercq, M. Blanc; Le Kremlin-Bicêtre, C. Goujard; Lille-Tourcoing, O. Robineau; Limoges, P. Weinbreck; Lyon, L. Cotte; D. Makhloufi; Marseille, I. Poizot-Martin, I. Ravaud; Montpellier, J. Reynes; Nancy, H. Fenaux; Nantes, F. Raffi; Nice, E. Cua, J. Durant, P. Pugliese; Orléans, L. Hocquelloux, T. Prazuck; Paris-Bichat Claude Bernard, Y. Yazdanpanah, R. Landman, S. Legac; Paris-HEGP, L. Weiss, M. Karmochkine; Paris-Jean-Verdier, S. Tassi; Paris-Necker-Enfants Malades, C. Duvivier ; HU ParisSud, C. Bolliot, M. Malet, D. Vittecoq, M. Raho-Moussa, M. Mole; Paris-Pitié-Salpêtrière, C. Katlama, A. Simon; Paris-Saint Antoine, P. M. Girard, J. L. Meynard; Paris-Saint Louis, J. M. Molina; Paris-Tenon, V. Berrebi, G. Pialoux; Pointe à Pitre, I. Lamaury, Fort de France , A. Cabié; Poitiers, G. Le Moal, D. Plainchamp; Rennes, F. Benezit, J.Vivent, C. Morlat, M. Poisson-Vannier; Rouen, F. Caron, Y. Debab, G. Unal Strasbourg, M. Partisani, D. Rey, P. Fischer; Toulouse, B. Marchou, P. Massip, P Delobel; Tours, G. Gras, G. Fajole; Versailles, A. Greber Belan, Ruel, O. Beletry, F. Granier.

\section{FUNDING}

This work was supported by the Agence Nationale de Recherches sur le SIDA et les Hépatites virales - Maladies Infectieuses Emergentes (ANRS - MIE, AC43) and ViiV Healthcare.

\section{TRANSPARENCY DECLARATIONS}

The authors have no conflict of interest. 


\section{REFERENCES}

290

291

292

293

294

295

296

297

298

299

300

301

302

303

304

305

306

307

308

309

310

311

312

313

1. Taiwo BO, Marconi VC, Berzins B, et al. Dolutegravir Plus Lamivudine Maintains Human Immunodeficiency Virus-1 Suppression Through Week 48 in a Pilot Randomized Trial. Clin Infect Dis 2018; 66: 1794-7.

2. Joly V, Burdet C, Landman R, et al. Dolutegravir and lamivudine maintenance therapy in HIV-1 virologically suppressed patients: results of the ANRS 167 trial (LAMIDOL). J Antimicrob Chemother 2019; 74: 739-45.

3. Aboud M, Orkin C, Podzamczer D, et al. Efficacy and safety of dolutegravir-rilpivirine for maintenance of virological suppression in adults with HIV-1: 100-week data from the randomised, open-label, phase 3 SWORD-1 and SWORD-2 studies. Lancet HIV 2019; 6: e576-87.

4. Margolis DA, Gonzalez-Garcia J, Stellbrink H-J, et al. Long-acting intramuscular cabotegravir and rilpivirine in adults with HIV-1 infection (LATTE-2): 96-week results of a randomised, openlabel, phase 2b, non-inferiority trial. Lancet 2017; 390: 1499-510.

5. Swindells S, Andrade-Villanueva J-F, Richmond GJ, et al. Long-Acting Cabotegravir and Rilpivirine for Maintenance of HIV-1 Suppression. N Engl J Med 2020; 382: 1112-23.

6. Orkin C, Arasteh K, Górgolas Hernández-Mora M, et al. Long-Acting Cabotegravir and Rilpivirine after Oral Induction for HIV-1 Infection. N Engl J Med 2020; 382: 1124-35.

7. van Wyk J, Ajana F, Bisshop F, et al. Efficacy and Safety of Switching to Dolutegravir/Lamivudine Fixed-Dose Two-Drug Regimen Versus Continuing a Tenofovir Alafenamide-Based Three- or Four-Drug Regimen for Maintenance of Virologic Suppression in Adults With HIV-1: Phase 3, Randomized, Non-inferiority TANGO Study. Clin Infect Dis 2020.

8. Cahn P, Madero JS, Arribas JR, et al. Dolutegravir plus lamivudine versus dolutegravir plus tenofovir disoproxil fumarate and emtricitabine in antiretroviral-naive adults with HIV-1 infection (GEMINI-1 and GEMINI-2): week 48 results from two multicentre, double-blind, randomised, noninferiority, phase 3 trials. Lancet 2019; 393: 143-55.

9. Cahn P, Madero JS, Arribas JR, et al. Durable Efficacy of Dolutegravir Plus Lamivudine in Antiretroviral Treatment-Naive Adults With HIV-1 Infection: 96-Week Results From the GEMINI1 and GEMINI-2 Randomized Clinical Trials. J Acquir Immune Defic Syndr 2020; 83: 310-8.

10. Raffi F, Babiker AG, Richert L, et al. Ritonavir-boosted darunavir combined with raltegravir or tenofovir-emtricitabine in antiretroviral-naive adults infected with HIV-1: 96 week results from the NEAT001/ANRS143 randomised non-inferiority trial. The Lancet 2014; 384: 1942-51.

11. Lambert-Niclot S, George EC, Pozniak A, et al. Antiretroviral resistance at virological failure in the NEAT 001/ANRS 143 trial: raltegravir plus darunavir/ritonavir or tenofovir/emtricitabine plus darunavir/ritonavir as first-line ART. J Antimicrob Chemother 2016; 71: 1056-62.

12. EACS AIDS Clinical Society. EACS guidelines version 10.0 (Nov. 2019). 2020. Available at: https://eacs.sanfordguide.com. 
13. Panel on Antiretroviral Guidelines for Adults and Adolescents. Guidelines for the Use of Antiretroviral Agents in Adults and Adolescents with HIV. Department of Health and Human Services.; 2020. Available at: http://www.aidsinfo.nih.gov/ContentFiles/ AdultandAdolescentGL.pdf.

14. Descamps D, Delaugerre C, Masquelier B, et al. Repeated HIV-1 resistance genotyping external quality assessments improve virology laboratory performance. J Med Virol 2006; 78: 153-60.

15. Marcelin A-G, Grude M, Charpentier C, et al. Resistance to integrase inhibitors: a national study in HIV-1-infected treatment-naive and -experienced patients. J Antimicrob Chemother 2019; 74: $1368-75$.

16. Fourati S, Charpentier C, Amiel C, et al. Cross-resistance to elvitegravir and dolutegravir in 502 patients failing on raltegravir: a French national study of raltegravir-experienced HIV-1-infected patients. J Antimicrob Chemother 2015; 70: 1507-12.

17. Modica S, Rossetti B, Lombardi F, et al. Prevalence and determinants of resistance mutations in HIV-1-infected patients exposed to integrase inhibitors in a large Italian cohort. HIV Med 2019; 20: $137-46$.

18. Scutari R, Alteri C, Vicenti I, et al. Evaluation of HIV-1 integrase resistance emergence and evolution in patients treated with integrase inhibitors. J Glob Antimicrob Res 2020; 20: 163-9.

19. Hurt CB, Sebastian J, Hicks CB, Eron JJ. Resistance to HIV integrase strand transfer inhibitors among clinical specimens in the United States, 2009-2012. Clin Infect Dis 2014; 58: 423-31.

20. Lepik KJ, Harrigan PR, Yip B, et al. Emergent drug resistance with integrase strand transfer inhibitor-based regimens. AIDS 2017; 31: 1425-34.

21. De Francesco MA, Izzo I, Properzi M, et al. Prevalence of Integrase Strand Transfer Inhibitors Resistance Mutations in Integrase Strand Transfer Inhibitors-Naive and -Experienced HIV-1 Infected Patients: A Single Center Experience. AIDS Res Hum Retroviruses 2018; 34: 570-4.

22. Cecchini DM, Castillo S, Copertari G, et al. Resistance to HIV integrase strand transfer inhibitors in Argentina: first interim survey. Rev Esp Quimioter 2019; 32: 263-7.

23. Doyle T, Dunn DT, Ceccherini-Silberstein F, et al. Integrase inhibitor (INI) genotypic resistance in treatment-naive and raltegravir-experienced patients infected with diverse HIV-1 clades. $J$ Antimicrob Chemother 2015; 70: 3080-6.

24. Hightower KE, Wang R, Deanda F, et al. Dolutegravir (S/GSK1349572) exhibits significantly slower dissociation than raltegravir and elvitegravir from wild-type and integrase inhibitor-resistant HIV-1 integrase-DNA complexes. Antimicrob Agents Chemother 2011; 55: 4552-9.

25. DeAnda F, Hightower KE, Nolte RT, et al. Dolutegravir interactions with HIV-1 integraseDNA: structural rationale for drug resistance and dissociation kinetics. PLoS One 2013; 8: e77448.

26. Llibre JM, Pulido F, García F, et al. Genetic barrier to resistance for dolutegravir. AIDS Rev 2015; 17: 56-64. 
27. Raffi F, Jaeger H, Quiros-Roldan E, et al. Once-daily dolutegravir versus twice-daily raltegravir in antiretroviral-naive adults with HIV-1 infection (SPRING-2 study): 96 week results from a randomised, double-blind, non-inferiority trial. Lancet Infect Dis 2013; 13: 927-35.

28. Pyngottu A, Scherrer AU, Kouyos R, et al. Predictors of virological failure and time to viral suppression of first line integrase inhibitor based antiretroviral treatment. Clin Infect Dis 2020. Clin Infect Dis 2020 Oct 24;ciaa1614. doi: 10.1093/cid/ciaa1614

29. Lagi F, Baldin G, Colafigli M, et al. Viro-immunological efficacy and tolerability of dolutegravir-based regimens compared to regimens based on other integrase strand inhibitors, protease inhibitors or non-nucleoside reverse transcriptase inhibitors in patients with acute HIV-1 


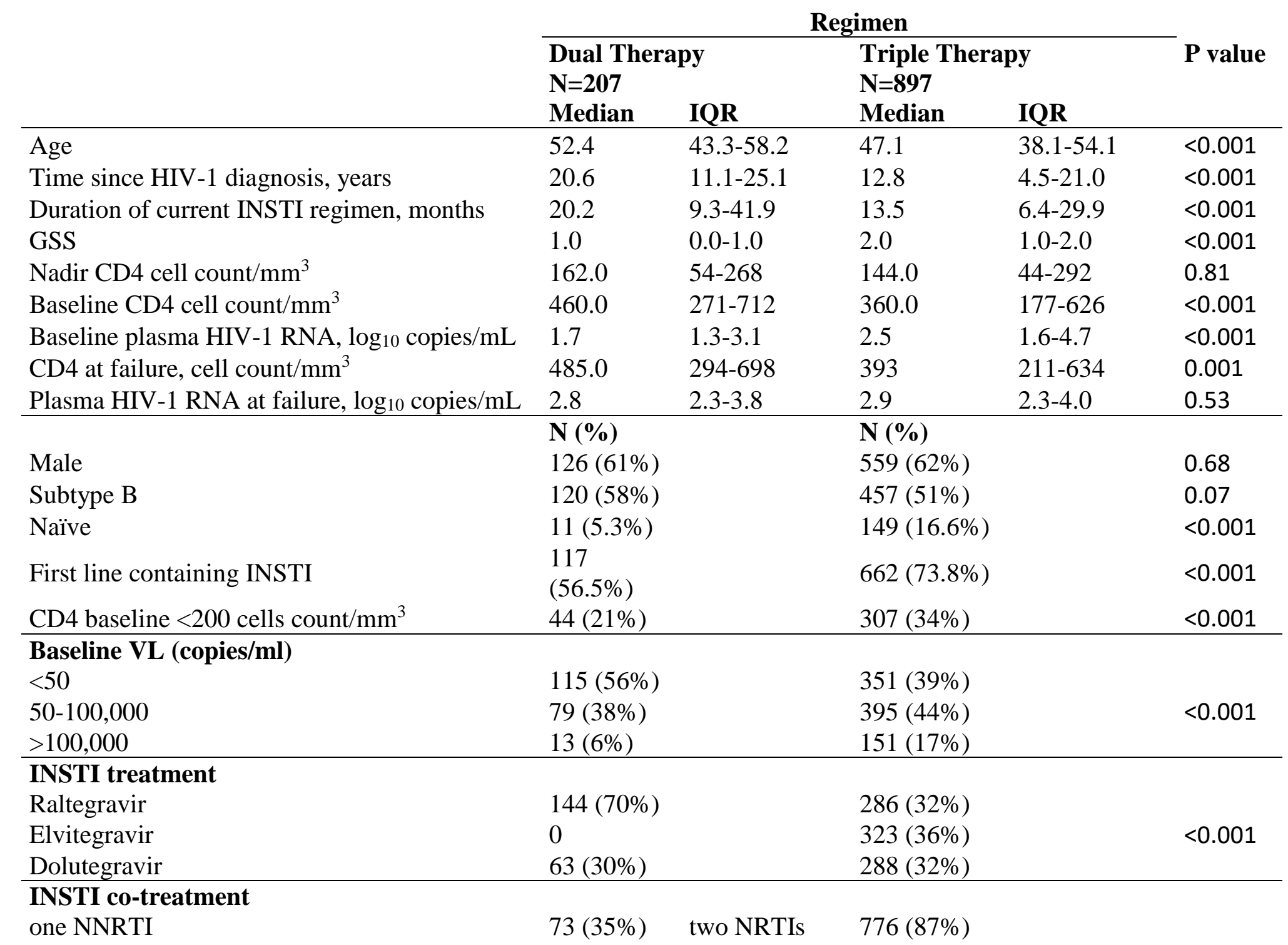




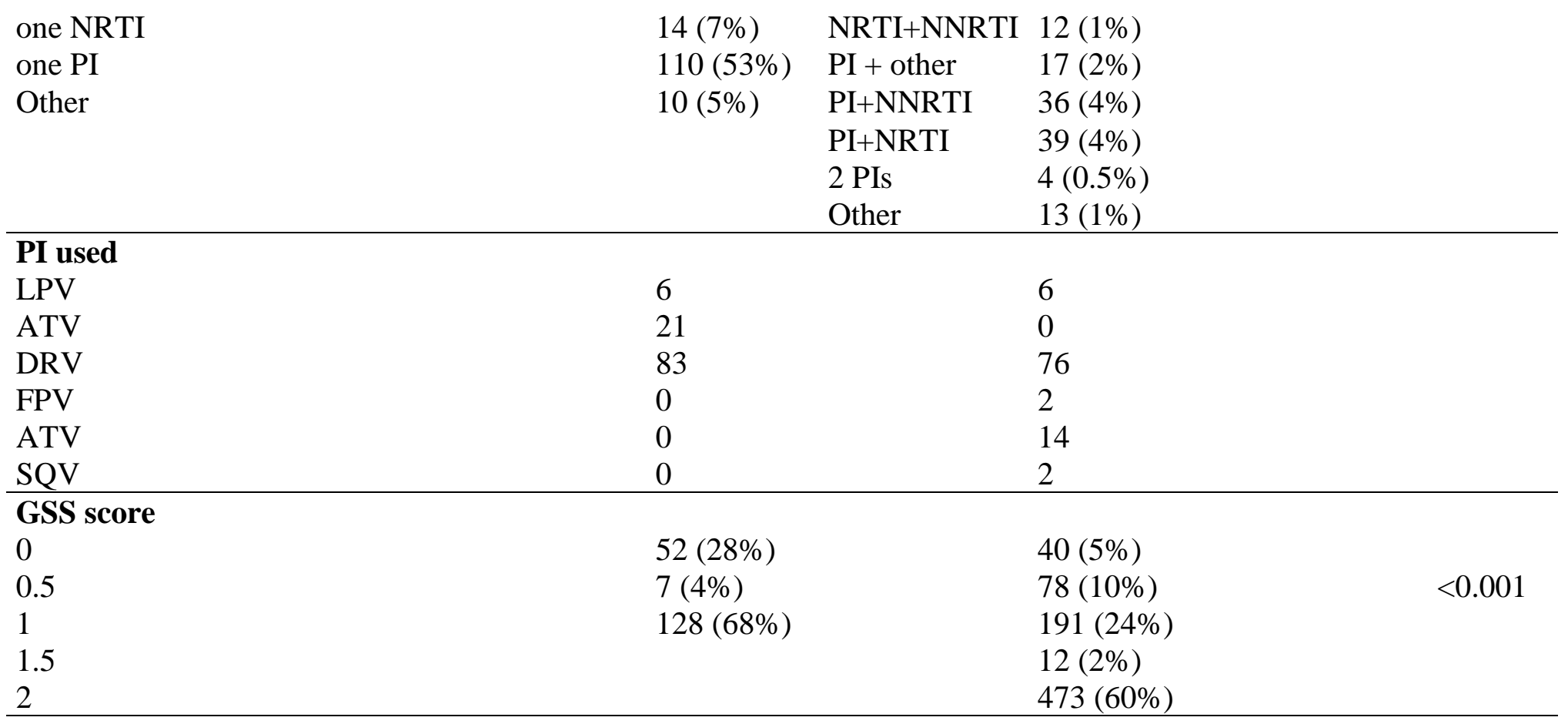


Table 2. Factors associated with the occurrence of at least one INSTI resistance associated mutations.

\begin{tabular}{|c|c|c|c|c|c|c|}
\hline \multirow[b]{3}{*}{ Triple vs. Dual therapy } & \multicolumn{3}{|c|}{ Univariate } & \multicolumn{3}{|c|}{ Multivariate } \\
\hline & OR & $95 \% \mathrm{CI}$ & P-value & OR & $95 \% \mathrm{CI}$ & \\
\hline & 0.59 & $0.44--0.8$ & 0.0007 & & & \\
\hline Age (per 10 years increase) & 1.02 & $0.92--1.13$ & 0.69 & & & \\
\hline CD4 baseline (per 100 cells $/ \mathrm{mm}^{3}$ increase) & 1.01 & $0.97--1.05$ & 0.69 & & & \\
\hline Nadir CD4 (per 100 cells $/ \mathrm{mm}^{3}$ increase) & 0.96 & $0.90--1.03$ & 0.22 & & & \\
\hline Log HIV RNA Failure (per $1 \log _{10}$ copies/ml increase) & 1.31 & $1.18--1.47$ & $<0.0001$ & 1.24 & $1.1--1.4$ & 0.001 \\
\hline Log HIV RNA baseline (per $1 \log _{10}$ copies/ml increase) & 0.96 & $0.89--1.04$ & 0.29 & & & \\
\hline Duration of INSTI treatment (per one-year increase) & 1.09 & $1.03--1.16$ & 0.003 & & & \\
\hline Duration of Infection (per 10 years increase) & 1.11 & $0.98--1.26$ & 0.09 & & & \\
\hline Subtype Non B vs B & 1.22 & $0.96--1.55$ & 0.10 & 1.75 & $1.3--2.3$ & 0.0002 \\
\hline GSS $1-1.5$ vs $0-0.5$ & 0.34 & $0.23--0.51$ & $<0.0001$ & 0.32 & $0.2--0.5$ & $<0.0001$ \\
\hline GSS 2 vs $0-0.5$ & 0.11 & $0.07--0.16$ & $<0.0001$ & 0.10 & $0.07-0.2$ & $<0.0001$ \\
\hline DTG vs RAL & 0.30 & $0.22--0.41$ & $<0.0001$ & 0.46 & $0.3--0.7$ & $<0.0001$ \\
\hline EVG vs RAL & 0.77 & $0.58--1.03$ & 0.08 & 1.28 & $0.9--1.8$ & 0.16 \\
\hline
\end{tabular}

INSTI, integrase strand transfer inhibitors; GSS, genotypic sensitivity score; DTG, dolutegravir; RAL, raltegravir; EVG, elvitegravir $\mathrm{P}$-value in bold is significant 
Figure 1. Prevalence of sequences with at least one INSTIs resistance associated mutations in the total dataset according to the INSTIs in the antiretroviral treatment.

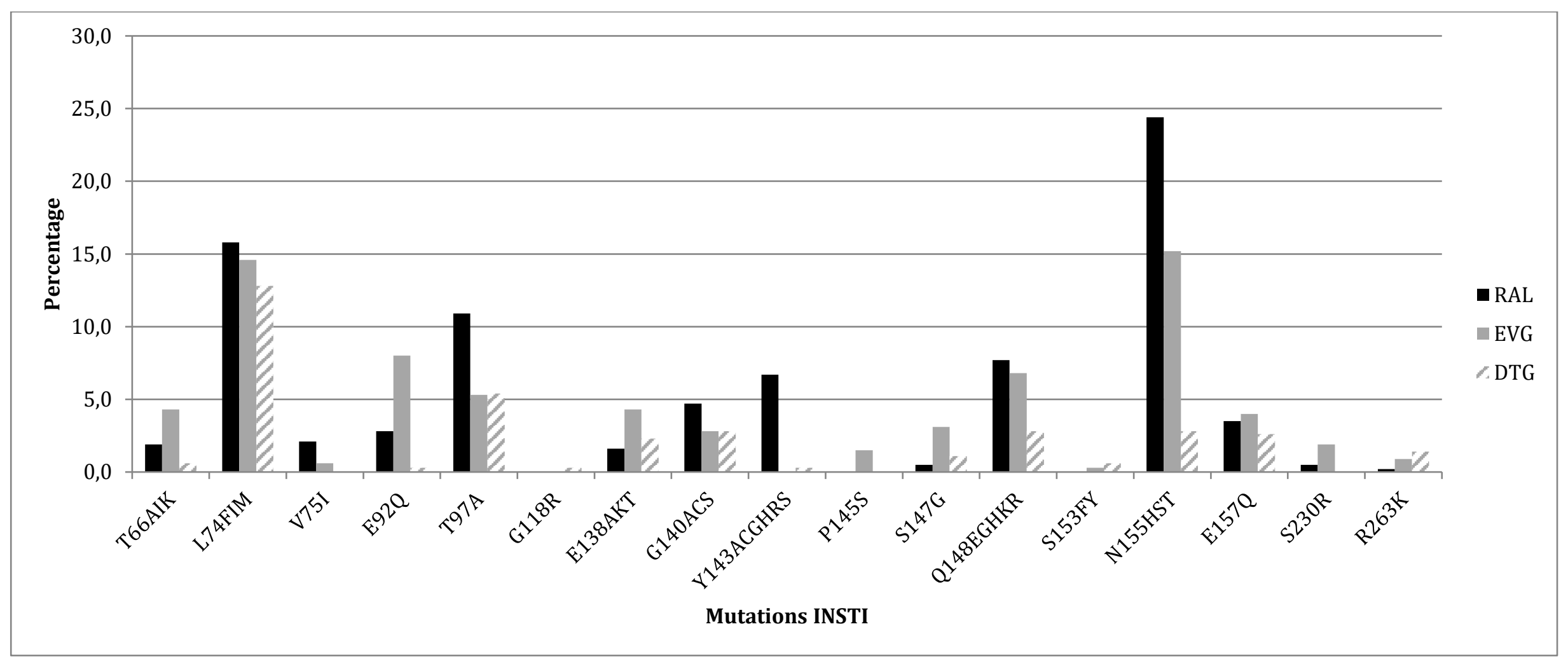


1 Figure 2. Genotypic interpretation of integrase resistance to different INSTIs among the 1104 patients failing an INSTI-containing

2 regimen. Predicted resistance to raltegravir (RAL), elvitegravir (EVG) and dolutegravir (DTG) according to the integrase sequence with

3 the ANRS algorithm.

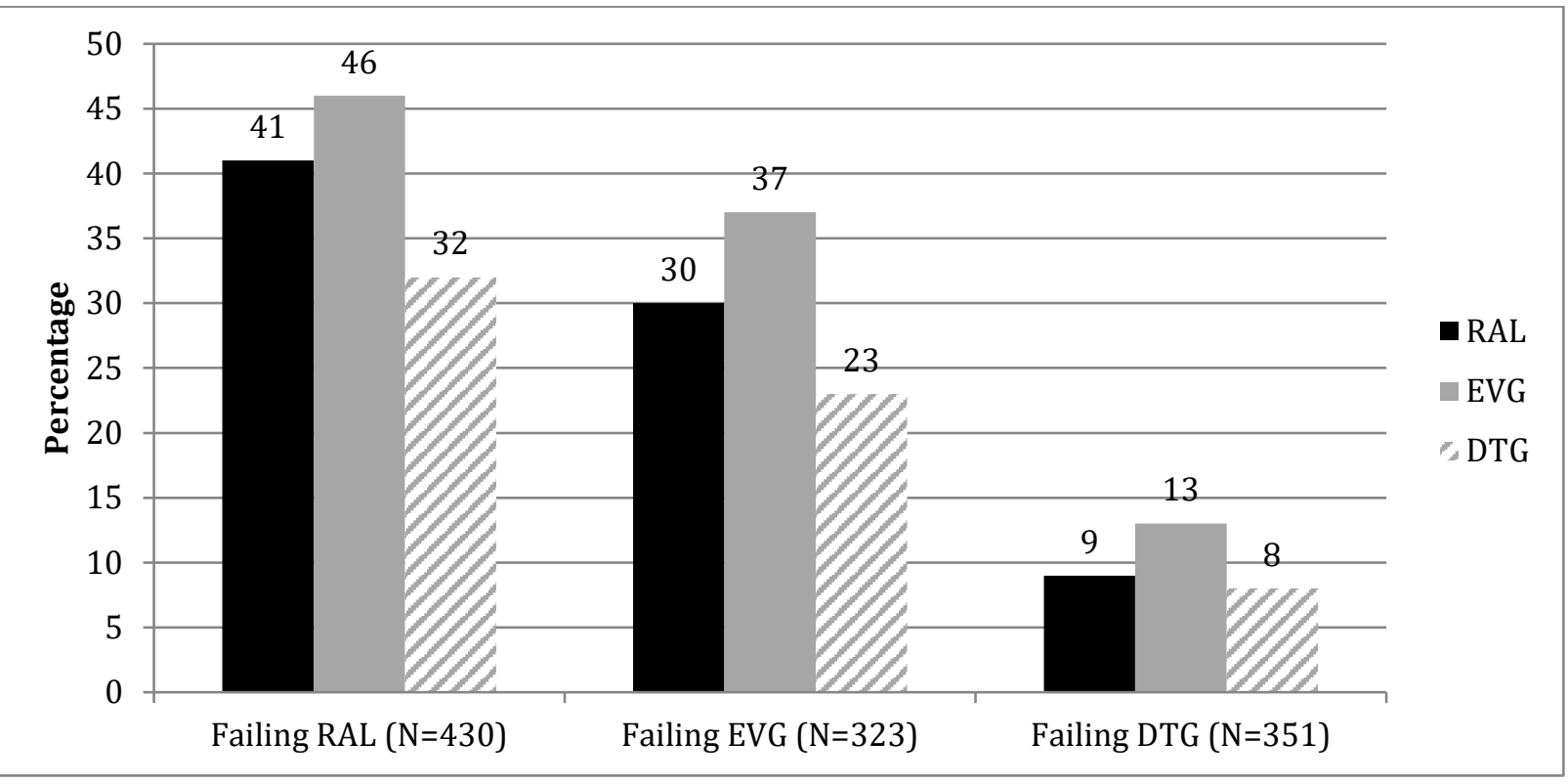


